\title{
Legacy and novel halogenated flame retardants in seawater and atmosphere of the Bohai Sea: Spatial trends, seasonal variations, and influencing factors
}

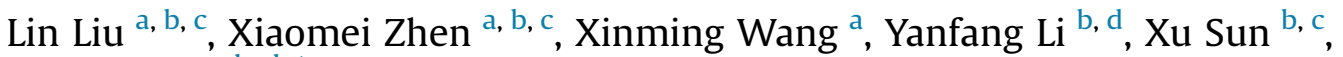 \\ Jianhui Tang ${ }^{b, d}, *$ \\ a State Key Laboratory of Organic Geochemistry, Guangzhou Institute of Geochemistry, Chinese Academy of Sciences (CAS), Guangzhou, 510640, China \\ ${ }^{\mathrm{b}}$ CAS Key Laboratory of Coastal Environmental Processes and Ecological Remediation, Shandong Key Laboratory of Coastal Environmental Processes, Yantai \\ Institute of Coastal Zone Research, Chinese Academy of Sciences, Yantai, 264003, China \\ ${ }^{c}$ University of Chinese Academy of Sciences, Beijing, 100049, China \\ d Center for Ocean Mega-Science, Chinese Academy of Sciences, Qingdao, 266071, China
}

\section{A R T I C L E I N F O}

Article history:

Received 15 April 2020

Received in revised form

21 June 2020

Accepted 25 June 2020

Available online 1 July 2020

\section{Keywords:}

DBDPE

Sediment resuspension

Phytoplankton blooms

Water stratification

Atmospheric deposition

Halogenated flame retardants

\begin{abstract}
A B S T R A C T
Seventeen halogenated flame retardants (HFRs) were concurrently analyzed in surface seawater and low atmospheric samples from the Bohai Sea during four research cruises. HFRs mainly existed in particulate phases, and in general decabromodiphenyl ethane (DBDPE) was the predominant compound in both air and water samples. Relatively high concentrations were observed in the water of Laizhou Bay (LB), where the largest manufacturing base of brominated flame retardants (BFRs) in China is located and weak water exchange occurs. Transport from LB by coastal currents may be the main source of BFRs in some areas without emission sources. The HFRs in seawater exhibited distinct seasonal variation, with significantly higher concentrations in winter than those in summer. The controlling factors include the resuspension of sediment induced by large wind waves in winter and phytoplankton scavenging in spring and seawater stratification in summer. HFRs composition varied largely in different seasons, due to the different extents of riverine input and atmospheric deposition. Normally, for air masses passing through the nearby industrial regions, high concentrations of DBDPE (up to $1780 \mathrm{pg} \mathrm{m}^{-3}$ ) co-existed with high total suspended particle (TSP) levels (up to $150 \mu \mathrm{g} \mathrm{m}^{-3}$ ). The estimated atmospheric deposition fluxes of HFRs were 19,51 , and $80 \mathrm{~kg}$ season ${ }^{-1}$ in spring, summer, and winter, respectively, indicating that the Bohai Sea is a sink of HFRs via atmospheric deposition. This study has increased our understanding of the behaviors and fates of the legacy and novel HFRs in the shallow coastal sea.
\end{abstract}

(c) 2020 Elsevier Ltd. All rights reserved.

\section{Introduction}

Halogenated flame retardants (HFRs) are used in a wide variety of commercial products, such as thermoplastics, furniture, electrical and electronic equipment, and construction products, to inhibit the ignition of flammable materials and reduce the spreading of flames (de la Torre et al., 2018). Polybrominated diphenyl ethers (PBDEs), which are typical brominated flame

\footnotetext{
* Corresponding author. CAS Key Laboratory of Coastal Environmental Processes and Ecological Remediation, Shandong Key Laboratory of Coastal Environmental Processes, Yantai Institute of Coastal Zone Research, Chinese Academy of Sciences, Yantai, 264003, China.

E-mail address: jhtang@yic.ac.cn (J. Tang).
}

retardants (BFRs), have been widely used for over 30 years (Shao et al., 2016). Owing to their persistence, capacities for bioaccumulation and long-range atmospheric transport (LRAT), and potential toxicity to human and ecosystem health, commercial penta-BDE, octa-BDE, and deca-BDE mixtures have been added to the list of persistent organic pollutants (POPs) under the Stockholm Convention (UNEP, 2018). With the gradual phasing out of PBDEs, several novel brominated flame retardants ( $n$ BFRs), such as decabromodiphenylethane (DBDPE), pentabromotoluene (PBT), pentabromoethylbenzene (PBEB), hexabromobenzene (HBB), have been introduced as alternatives. Dechlorane Plus (DP) (syn- and anti-isomers), a new chlorinated flame retardant, has been used in plastic connectors, wires, and cable coatings (Zhen et al., 2018; Li et al., 2017). With widespread application, this chemical 
inevitably leached into the environment. These compounds have been detected in the air (Li et al., 2016a; Ma et al., 2017; Lee et al., 2016), sediment (Zhen et al., 2018; Wang and Kelly, 2017), water (Wang et al., 2017a; Su et al., 2017), and biota samples (Tao et al., 2017; Qiao et al., 2017; Jin et al., 2016), or even in the remote plateau (Ma et al., 2017) and polar regions (Carlsson et al., 2018; Aznar-Alemany et al., 2018) through the LRAT. Growing evidence suggests that these novel flame retardants also have the properties of POPs, and hence pose a threat to ecosystems and human health.

The Bohai Economic Rim is one of the most prosperous regions in China and it accounted for $1 / 4$ of GDP, top 6 among the 10 busiest harbors, $12 \%$ of area and $20 \%$ population of China in 2018 . There are also 13 megacities around the Bohai Sea. Bohai Sea is a shallow, semienclosed marginal sea of the western Pacific Ocean with a narrow strait to the Yellow Sea (Shao et al., 2016), and is divided into the Bohai Bay (BB), the Laizhou Bay (LB), the Liaodong Bay (LDB) and the center of the Bohai Sea (CBS) in this study. The sea is experiencing water quality deterioration due to the large amount of nutrients and pollutants from land-based sources. Eutrophication, hypoxia, and harmful algal blooms, together with the high level of POPs in certain areas, are frequently reported (Wang et al. 2009, Wang et al., 2017a; Zhao et al., 2017; Wei et al., 2004). Bohai Sea is still under the influencing of the eastern Asia monsoon. Mean wind directions from north to northwest prevail in winter, whereas in summer favored wind directions are from the south (Hainbucher et al., 2004). PBDEs are typical POPs that were mainly produced in the Laizhou Bay area, where the largest BFR manufacturing base in China is located and high levels of PBDEs and other BFRs have been widely detected in the nearby soil, atmosphere, biota and sediment samples (Zhen et al. 2016, 2018; Jin et al. 2008, 2009; Pan et al. 2010, 2011). A recently study reported the occurrence of BFRs in a coastal maricultural area near Dalian City (Wang et al., 2017a). However, to the best of our knowledge, no studies have been conducted on the levels of HFRs in seawater or the atmosphere across the whole Bohai Sea. The investigation of HFRs in the coastal sea nearby the manufacturing base could explain the impact of HFRs manufacturing on surrounding environment. The contaminations may spread to a large scale by some hydrodynamic factors. Therefore, it is imperative to understand the environmental fate of HFRs in the Bohai Sea.

Since the phasing out of decaBDE, local plants have quickly switched to producing DBDPE and other unregulated BFRs to fill the gap in the market. Based on similar structures and physicochemical properties (low volatility, low water solubility, and a high $\mathrm{K}_{\mathrm{ow}}$ ) between DBDPE and BDE209, DBDPE became commercially important as an alternative to the Deca-BDE formulation in the early 1990s (Covaci et al., 2011). While DBDPE appears to be less sensitive to thermal degradation and photo degradation than BDE209, which means the longer lifetime and more difficult to degrade in environment (Kierkegaard et al., 2009). In China, the production of DBDPE has increased by $80 \%$ per year since 2006 , reaching 12,000 $\mathrm{t}$ (Qi et al., 2014). This dramatic shift has had a profound effect on the environmental distribution of HFRs, and the predominance of DBDPE over other HFRs in the air has been reported (Zhao et al., 2013). However, little data are available about the distributions of legacy and emerging HFRs in this environmentally, economically, and ecologically important coastal sea.

In this study, HFR concentrations were measured in seawater and air in August and December 2016, and February and June 2017, in the Bohai Sea. Although the sampling days are different (9 days in August; 9 days in December; 4 days in February and 5 days in June) in each research period due to weather condition and logistical reason, the cruises covered most of the Bohai Sea (see Fig. S1). Overall, 29 seawater and 27 air samples were collected to investigate the spatial and temporal trends of HFRs and to explore the influential factors and potential sources in the Bohai Sea.

\section{Method and materials}

\subsection{Sample collection}

Twenty-seven air samples (approximately $300 \mathrm{~m}^{3}$ each) and twenty-nine seawater samples (approximately $60 \mathrm{~L}$ each) were collected onboard a research vessel (Chuangxin I) from the Bohai Sea during four sampling campaigns. Paired air and surface water samples were collected in August, December and February. However, on the two of cruises in June 2017, within sampling time of each atmospheric sample ( $24 \mathrm{~h}$ ), two surface water samples were collected separately due to the long-journey of those air samples. Maps of the sampling tracks for each sample are presented in Fig. S1 (A, B, C, and D). More details related to sample collection are given in supporting information (SI).

\subsection{Sample preparation and instrumental analysis}

Prior to extraction, the glass microfiber filters were freeze-dried, and 10 -ng ${ }^{13} \mathrm{C}$-HBB and 8-ng PCB209 were used as surrogate standards. Activated copper was added to the extraction solvent to eliminate the influence of elemental sulfur. The samples were extracted using a modified Soxhlet extractor with DCM for $24 \mathrm{~h}$. The water column extracts were frozen to eliminate remaining water as best as possible. The volume of the extracts was reduced by rotary evaporation to $2-3 \mathrm{~mL}$, and the extracts were then rotary evaporated to approximately $1 \mathrm{~mL}$ after changing the solvent to hexane. The 1 -mL extracts were purified using 2.5 -g silica gel columns $(10 \%$ water deactivated) topped with $3 \mathrm{~g}$ of anhydrous sodium sulfate. The columns were eluted with $22 \mathrm{~mL}$ of hexane and then reduced to a final volume of $100 \mu \mathrm{L}$ with nitrogen (purity 99.999\%). The solvent was spiked with $20 \mathrm{ng}$ of BDE77 as the internal standard prior to chemical analysis.

HFRs chemical analyses were performed with an Agilent 7890 gas chromatograph (GC) coupled with a 5975C mass selective detector (MSD) in electron capture negative ion chemical ionization mode (ECNICI). The details on analytical method have been given in the SI.

\subsection{Quality assurance and quality control}

Field blanks for the three types of sample different periods were collected at different periods during the campaigns (Table S1), and laboratory blanks were also added during the experiment (Table S2). The recovery rates were monitored throughout the analytical measurements. For the all-filter samples, the mean recovery rates for ${ }^{13} \mathrm{C}$-HBB and PCB209 were $106 \pm 22 \%$ and $97 \pm 20 \%$, respectively. For the water column samples, the mean recovery rates for ${ }^{13} \mathrm{C}-\mathrm{HBB}$ and PCB 209 were $113 \pm 20 \%$ and $105 \% \pm 22 \%$, respectively. For the air columns, the mean recovery rates for ${ }^{13} \mathrm{C}$-HBB and PCB 209 were $122 \pm 25 \%$ and $106 \% \pm 25 \%$, respectively. The method detection limits (MDL) were calculated based on the mean blank values plus three times their standard deviations. In this study, the values below the MDLs were considered to be "not detected" (n.d.). The MDL ranges of PBDEs, $n$ BFRs, and DPs for the seawater filters were $0.049-1.6 \mathrm{pg} \mathrm{L}^{-1}$, $0.065-20 \mathrm{pg} \mathrm{L}^{-1}$, and $0.025-0.040 \mathrm{pg} \mathrm{L}^{-1}$, respectively. For the air filters, the MDL ranges of these compounds were $0.0098-0.32 \mathrm{pg} \mathrm{m}^{-3}, 0.013-4.0 \mathrm{pg} \mathrm{m}^{-3}$, and $0.0049-0.0081 \mathrm{pg} \mathrm{m}^{-3}$, respectively. For the seawater columns, the MDL ranges in the dissolved phase were $0.016-4.4 \mathrm{pg} \mathrm{L}^{-1}, 0.022-23 \mathrm{pg} \mathrm{L}^{-1}$, and $0.047-0.060 \mathrm{pg} \mathrm{L}^{-1}$, respectively. Finally, for the air columns, the MDL ranges were $0.013-0.25 \mathrm{pg} \mathrm{m}^{-3}, 0.0017-3.7 \mathrm{pg} \mathrm{m}^{-3}$, and $0.0041-0.0061 \mathrm{pg} \mathrm{m}^{-3}$ in gas phase, respectively.

To further explore the HFRs contamination by ship-based emissions, we added a set of comparative sampling and 
experiments. The details are given in the SI. There were very few HFRs from ship's outgassing (Table S3). To assess the influence of stack emissions, we actually measured the height of stacks $(9 \mathrm{~m}$ above sea level), which were located near the stern of the ship. An air sampler was mounted at the bow of the ship, and the installation height was $11.5 \mathrm{~m}$ above sea level. In summary, the ship is not an obvious source of contamination in the study.

\subsection{Hydrodynamic model}

The hydrodynamic conditions were predicted using the Regional Ocean Modeling System (ROMS), which is a threedimensional, free-surface, finite difference, nonlinear hydrodynamic model (Haidvogel et al., 2000; Warner et al., 2008). The model encompassed the Bohai Sea from $37^{\circ} \mathrm{N}$ to $41.05^{\circ} \mathrm{N}$ and from $117.5^{\circ} \mathrm{E}$ to $122.5^{\circ} \mathrm{E}$ with a grid resolution of 2' (Li et al., 2016b), and has been described in details in the SI.

\subsection{Air mass back trajectories}

To elucidate the general source regions of the HFRs in the air samples, air mass backward trajectories (BTs) were modeled using NOAA's HYSPLIT model (Draxler and Rolph, 2003) to trace the probable paths of the air masses associated with the samples. The air mass BTs were calculated for $120 \mathrm{~h}$ at approximately $6 \mathrm{~h}$ intervals. The individual BTs are shown in Fig. S2.

\section{Results and discussion}

\subsection{HFR levels in seawater and air}

The concentrations of PBDEs, $n$ BFRs, and DPs in seawater and the atmosphere are summarized in Table 1 and presented in detail in Tables S4-S7. In this study, BDE28, 47, 99, 100, 153, 154, and 183 were described as $\sum_{7}$ PBDEs.

In seawater, the overall $\sum$ PBDEs concentrations including both dissolved and particle phase were within the range of $3.3-290 \mathrm{pg} \mathrm{L}^{-1}$, with an average of $70 \pm 67 \mathrm{pg} \mathrm{L}^{-1}$. BDE209 (range: 1.7-290 pg L ${ }^{-1}$, mean: $68 \pm 68 \mathrm{pg} \mathrm{L}^{-1}$ ) was the dominant PBDE congener, accounting for approximately $98 \%$ of the PBDEs, followed by BDE47 (approximately 0.8\%). A similar composition was observed previously in seawater near coastal mariculture in the Bohai Sea (Wang et al., 2017a) and Jiaozhou Bay in the Yellow Sea (Ju et al., 2016). The total concentrations of $n$ BFRs ranged from 9.2 to $623 \mathrm{pg} \mathrm{L}^{-1}$, with a mean value of $120 \pm 170 \mathrm{pg} \mathrm{L}^{-1}$. DBDPE (range: $n$.d. - 622 pg L ${ }^{-1}$, mean: $110 \pm 174 \mathrm{pg} \mathrm{L}^{-1}$ ) was the predominant compound, accounting for $96 \%$ of the total $n$ BFRs, which was higher than those of BDE209 in water samples. Both DBDPE and BDE209 were mainly present in suspended particulate matters (SPM, > 84\%). After DBDPE, the proportion of PBEB in the water samples was $3 \%$. Synand anti-DP were also found in the water samples at concentrations ranging from n.d. to $0.76 \mathrm{pg} \mathrm{L}^{-1}$ and $0.080-7.1 \mathrm{pg} \mathrm{L}^{-1}$, with a mean value of $0.16 \pm 0.17 \mathrm{pg} \mathrm{L}^{-1}$ and $0.93 \pm 1.5 \mathrm{pg} \mathrm{L}^{-1}$, respectively.

The total atmospheric concentrations (gas and particle phases) of PBDEs, $n$ BFRs, and DPs measured in the Bohai Sea were within ranges of $0.47-440 \mathrm{pg} \mathrm{m} \mathrm{m}^{-3}, 0.30-2000 \mathrm{pg} \mathrm{m}^{-3}$, and $0.032-2.6 \mathrm{pg} \mathrm{m}^{-3}$, respectively. Most HFRs were presented in total suspended particulates (TSPs), accounting for 95\%. BDE209 (range: 0.24-430 pg m${ }^{-3}$, mean: $41 \pm 95 \mathrm{pg} \mathrm{m}^{-3}$ ) and DBDPE (range: n.d. $180 \mathrm{pg} \mathrm{m}^{-3}$, mean: $140 \pm 370 \mathrm{pg} \mathrm{m}^{-3}$ ) were also the predominant compounds among the PBDEs and $n$ BFRs, accounting for $99 \%$ and $90 \%$, respectively. Similar to seawater, the concentrations of DBDPE were higher than those of BDE209 (Table 1), indicating its overwhelming production and application around the Bohai Sea. The detection levels of BDE183 (range: n.d. - $0.75 \mathrm{pg} \mathrm{m}^{-3}$, mean: $0.21 \pm 0.22 \mathrm{pg} \mathrm{m}^{-3}$ ), BDE47 (range: n.d. - $0.82 \mathrm{pg} \mathrm{m}^{-3}$, mean: $0.12 \pm 0.16 \mathrm{pg} \mathrm{m}^{-3}$ ), HBB (range: n.d. - $161 \mathrm{pg} \mathrm{m}^{-3}$, mean: $13 \pm 35 \mathrm{pg} \mathrm{m}^{-3}$ ), and PBT (range: $0.074-51 \mathrm{pg} \mathrm{m}^{-3}$, mean: $2.6 \pm 9.6 \mathrm{pg} \mathrm{m}^{-3}$ ) were relatively higher than those of the other compounds (excluding BDE209 and DBDPE).

Very limited data regarding BFRs are available for seawater samples, which is partially due to their physicochemical properties, i.e., their low volatility, low water solubility, and high $\mathrm{K}_{\mathrm{ow}}$ (Table S8). Several previous studies conducted worldwide are summarized in Table S9. The concentrations including BDE209 in four bays near Gal Island, South Korea (n.d. - 740 pg L $^{-1}$ ) (Gu et al., 2017), Izmir Bay, Turkey (0.20-190 pg L ${ }^{-1}$ ) (Cetin and Odabasi, 2007), and San Francisco Estuary (3-510 pg L ${ }^{-1}$ ) (Daniel et al., 2005) were in the same order of magnitude as the results of this study. However, the levels of PBDEs in China's seas, such as those in

Table 1

Concentrations of halogenated flame retardants in air (particle and gas phases, $\mathrm{pg} \mathrm{m}^{-3}$ ) and aqueous phase (particle and dissolved phases, pg $\mathrm{L}^{-1}$ ) in the Bohai Sea.

\begin{tabular}{|c|c|c|c|c|c|c|c|c|}
\hline \multirow[t]{2}{*}{ Compounds } & \multicolumn{4}{|l|}{ Water } & \multicolumn{4}{|l|}{ Air } \\
\hline & particulate & $\mathrm{M} \pm \mathrm{SD}$ & dissolved & $\mathrm{M} \pm \mathrm{SD}$ & particulate & $M \pm S D$ & gas & $\mathrm{M} \pm \mathrm{SD}$ \\
\hline BDE28 & n.d.-0.136 & $0.039 \pm 0.048$ & n.d.-6.64 & $0.361 \pm 1.21$ & n.d.-0.052 & $0.012 \pm 0.014$ & n.d.-0.749 & $0.067 \pm 0.146$ \\
\hline BDE47 & n.d.-0.824 & $0.061 \pm 0.176$ & n.d.-3.92 & $0.556 \pm 0.954$ & n.d. -0.141 & $0.043 \pm 0.046$ & n.d. -0.724 & $0.073 \pm 0.141$ \\
\hline BDE100 & n.d.-0.089 & $0.007 \pm 0.022$ & n.d.- -0.334 & $0.039 \pm 0.082$ & n.d. -0.171 & $0.029 \pm 0.045$ & n.d. -0.205 & $0.014 \pm 0.04$ \\
\hline BDE99 & n.d.-0.213 & $0.012 \pm 0.042$ & n.d.-0.209 & $0.033 \pm 0.059$ & n.d. -0.248 & $0.038 \pm 0.053$ & n.d.-0.164 & $0.021 \pm 0.041$ \\
\hline BDE154 & n.d. & & n.d.-0.214 & $0.059 \pm 0.069$ & n.d.-0.256 & $0.03 \pm 0.071$ & n.d. -0.081 & $0.014 \pm 0.023$ \\
\hline BDE153 & n.d.-0.305 & $0.049 \pm 0.090$ & n.d. -0.245 & $0.067 \pm 0.065$ & n.d. -0.140 & $0.037 \pm 0.043$ & n.d. -0.034 & $0.005 \pm 0.009$ \\
\hline BDE183 & n.d. -4.420 & $0.366 \pm 0.936$ & n.d.-1.93 & $0.125 \pm 0.357$ & n.d.-0.692 & $0.190 \pm 0.211$ & n.d. -0.098 & $0.015 \pm 0.024$ \\
\hline BDE209 & $1.73-223$ & $57.1 \pm 59.5$ & n.d.-77.9 & $11.2 \pm 19.2$ & n.d. -432.5 & $39.6 \pm 95.5$ & n.d. -12.8 & $1 \pm 2.57$ \\
\hline$\sum$ PBDES & $1.70-22.3$ & $7.51 \pm 5.97$ & $0.089-8.67$ & $2.26 \pm 2.70$ & n.d. -44.8 & $4.34 \pm 9.80$ & $0.038-1.43$ & $0.309 \pm 0.369$ \\
\hline PBT & n.d. -0.557 & $0.120 \pm 0.127$ & n.d.-1.97 & $0.533 \pm 0.539$ & $0.008-43.1$ & $2.00 \pm 8.25$ & $0.053-7.44$ & $0.622 \pm 1.430$ \\
\hline PBEB & n.d.- 0.435 & $0.015 \pm 0.081$ & n.d.-17.33 & $3.39 \pm 5.44$ & n.d.-1.53 & $0.139 \pm 0.299$ & n.d.-0.181 & $0.038 \pm 0.065$ \\
\hline DPTE & n.d.-0.259 & $0.019 \pm 0.060$ & n.d.-1.67 & $0.269 \pm 0.375$ & n.d.-0.464 & $0.047 \pm 0.121$ & n.d. -1.790 & $0.159 \pm 0.434$ \\
\hline HBB & n.d. & & n.d. & & n.d.-154 & $9.30 \pm 31.1$ & n.d.-74.08 & $3.71 \pm 14.50$ \\
\hline TBB & n.d.-1.960 & $0.118 \pm 0.375$ & n.d.-1.021 & $0.105 \pm 0.210$ & n.d. -0.352 & $0.047 \pm 0.080$ & n.d. -0.271 & $0.039 \pm 0.064$ \\
\hline TBE(BTBPE) & n.d. -0.486 & $0.104 \pm 0.161$ & n.d.-0.539 & $0.107 \pm 0.163$ & n.d. -0.372 & $0.098 \pm 0.104$ & n.d.-0.096 & $0.007 \pm 0.021$ \\
\hline DBDPE & n.d.-578 & $104 \pm 160$ & n.d.-91.44 & $6.27 \pm 18.5$ & n.d.-1778 & $138 \pm 369$ & n.d.-21.40 & $2.78 \pm 5.08$ \\
\hline$\sum$ NBFRs & n.d. -578 & $104 \pm 160$ & $0.042-92.1$ & $10.7 \pm 18.3$ & $0.194-1978$ & $149 \pm 404$ & $0.098-95.9$ & $7.36 \pm 18.6$ \\
\hline syn-DP & n.d.-0.626 & $0.126 \pm 0.130$ & n.d.- -0.567 & $0.031 \pm 0.108$ & $0.004-1.008$ & $0.083 \pm 0.197$ & n.d.-0.071 & $0.006 \pm 0.015$ \\
\hline anti-DP & $0.084-5.59$ & $0.656 \pm 1.008$ & n.d.-4.92 & $0.272 \pm 0.939$ & $0.019-1.83$ & $0.290 \pm 0.486$ & n.d. -0.478 & $0.056 \pm 0.129$ \\
\hline DPs & $0.084-6.22$ & $0.782 \pm 1.120$ & n.d. -5.49 & $0.303 \pm 1.044$ & $0.025-2.59$ & $0.373 \pm 0.645$ & n.d. -0.511 & $0.062 \pm 0.139$ \\
\hline
\end{tabular}

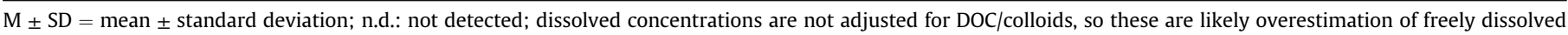
concentrations. 
Jiaozhou Bay (1200-5500 pg L ${ }^{-1}$ ) (Ju et al., 2016), Sanggou Bay (510-6200 pg L ${ }^{-1}$ ) (Ge et al., 2018), and the coastal mariculture area of the Bohai Sea (1500-6600 pg L ${ }^{-1}$ ) (Wang et al., 2017a) were much higher than those in our study. This may be due to the dilution of organic pollutants from the coastal area to the open sea, and it reflected higher production of HFRs in China. There are few data available on HFRs in the atmosphere above oceans, particularly in the Chinese coastal environment. The levels of 13 PBDEs (excluding BDE209) in the atmosphere of the Yangtze River Delta ranged from 0.20 to $43 \mathrm{pg} \mathrm{m}^{-3}$ during all four seasons (Zhang et al., 2016), which was higher than those observed in this study ( $\sum_{7}$ PBDEs: $0.089-2.9 \mathrm{pg} \mathrm{m}^{-3}$ ). This could be due to the different sampling sites, as the Yangtze River Delta is closer to land and easily polluted by anthropogenic sources. PBDE concentrations in the atmosphere above open oceans, such as the North Sea (six PBDEs including BDE209, 0.20-11 $\mathrm{pg} \mathrm{m}^{-3}$ ) (Möller et al., 2012), were much lower than those observed in our study $\left(0.47-440 \mathrm{pg} \mathrm{m}^{-3}\right)$.

In terms of the environmental fate of DP, the ratio $f_{\text {syn }}$ values have been discussed in SI. Due to HFRs are mainly presented in particulate phase, the following discussion will focus on BDE209, DBDPE, DPs in the particulate phase.

\subsection{Spatial and temporal trends}

\subsubsection{Spatial variations}

Spatial distributions of the dominant compounds in seawater and atmosphere of the Bohai Sea are shown in Fig. 1 and Fig. S3. In general, higher concentrations of BDE209, DBDPE, and DPs were detected near the $\mathrm{BB}$ and the LB than those in the LDB and the CBS in both summer (August) and winter (December) (Fig. 1A-D).The largest manufacturing base of BFRs in China is located near the LB area (Zhen et al., 2018). Technical deca-BDE mixtures and DBDPE are the predominant commercial products here (Jin et al., 2008; Covaci et al., 2011). BB receives a large amount of industrial wastewater, domestic sewage and exhausted gas from the BeijingTianjin-Hebei megalopolis (Zheng et al., 2016; Dong et al., 2015). The target compounds in LDB with obviously lower concentrations because of less emission and population compared to those in LB and $\mathrm{BB}$. This suggests that the pollution discharged from the sites around LB and BB is the main source of BFRs in the Bohai Sea area (Zhen et al., 2018; Su et al., 2017; Gu et al., 2017; Zheng et al., 2016).

Fig. 2 shows the surface currents in August and December, 2016 in the Bohai Sea, which are predicted using ROMS. The simulated water circulations varied largely. In summer, the highest concentrations of BFRs were measured in the mouth of BB area (Fig. 1A), which were in the path of the current from the pollutant sources of LB (Fig. 2). Meanwhile, the current in BB polluted by BeijingTianjin-Hebei megalopolis were speeding up at mouth of the bay and met the currents from LB. In contrast, the current from Bohai Strait passed through the LDB, which affected the current from LB, resulting in particularly small concentrations of BFRs in the LDB. In winter, the highest abundances were measured at the east bank of LB (Fig. 1C), where the essential path of the current from the LB was located. In addition, the active coastal resuspension intensify in the shallow water induced by winter monsoon, which are the major factors resulting the long-distance transport of the particulates from the Bohai Sea to the Yellow Sea (Qiao et al., 2016; Li et al., 2019). Thus, for areas not strongly affected by production sources, transportation from highly polluted waters through coastal currents or water masses could further aggravate the risk of contamination and lead to widespread pollution in the marine ecosystem.

\subsubsection{Seasonal patterns of HFRs in seawater}

As shown in Fig. 3, there were significant seasonal variations in the levels of the major HFRs (BDE209, DBDPE, and DPs), with relatively higher concentrations during the winter (December 2016, mean: $380 \pm 270 \mathrm{pg} \mathrm{L}^{-1}$ ) and winter-spring (February 2017, mean: $190 \pm 120 \mathrm{pg} \mathrm{L}^{-1}$ ) seasons, and lower concentrations in the springsummer (June 2017, $18 \pm 4.0 \mathrm{pg} \mathrm{L}^{-1}$ ) and summer (August 2016, $45 \pm 27 \mathrm{pg} \mathrm{L}^{-1}$ ) seasons. All compounds exhibited clear seasonality in seawater. In our study, the SPM concentration was an important factor determining this variability. A high correlation $(P<0.01)$ between the concentrations of DBDPE and SPM was found (Table S11, Fig. 3). In the shallow Bohai Sea (mean depth of $18 \mathrm{~m}$ ), the SPM concentrations are typically high in winter-spring and significantly lower in summer. This was consistent with the active coastal resuspension induced by energetic wave action in the shallow water (Wang et al., 2014a). According to the sediment concentrations of HFRs measured in summer of 2014, the range of HFRs concentrations and mean values in SPM were similar to what were collected for the sediment in the Bohai Sea (Tables S12 and S13). The mean concentrations of targets per SPM in winter were slightly higher than those in sediment because of the energetic wave actions. It suggested that the coastal resuspension of sediment could be one of important causes increasing the concentrations of hydrophobic organic contaminations (HOCs) in surface water. In addition, wind waves are a prominent feature of the Bohai Sea (dominant nearshore wave height: $0.3-0.7 \mathrm{~m}$; wave height in Bohai Strait and the central basin: approximately $1.0 \mathrm{~m}$ ) (Jiang et al., 2000). The winter northerly wind events, especially the winter storms with high waves, were the major factors influencing resuspension and transport in shallow regions, such as BB and LB (Qiao et al., 2016; Yang et al., 2011). Hence, the concentration of HFRs in the surface seawater increased with the resuspension of particulate matter, which was in response to the seasonal variation of the East Asian monsoon in this region (Hainbucher et al., 2004; Yang et al., 2011). Other possible causes, including the phytoplankton scavenging effect and water stratification during summer, should not be overlooked. In the Bohai Sea, there is a positive correlation $(\mathrm{P}<0.01)$ between SPM and particulate organic carbon (POC), which is mainly affected by phytoplankton (Wang et al., 2018). Some studies reported that the highest annual mean biomass and primary production of phytoplankton were found in LB and the CBS, and the seasonal succession was characterized by high biomass in spring followed by a sudden depletion (Wei et al., 2004; Lu et al., 2018; Sun et al., 2001). Hence, the annual variations in the chlorophyll-a concentration of surface water were analyzed at a station in LB and the CBS, respectively. High Chl a levels occurred in June, but the abundance decreased in August (Fig. S4). It has been reported that when the amount of particles is higher, enhanced settling flux induces a depletion of hydrophobic pollutants by scavenging and thus lowering the water concentrations (Berrojalbiz et al., 2011). The large amount of POC produced in spring is expected to adsorb HFRs and deposited during the phytoplankton extinction process, which was one reason for the reduced concentration of pollutants in surface water and the lowest levels in summer. A study indicated that less substance exchange occurs between the surface and bottom seawaters due to the stratification effect in summer (Zhong et al., 2017). According to the vertical variations in temperature and salinity collected from stations SW3 and SW4 near the LDB in summer (Fig. S5), significant decreases in the HFR concentrations were observed in two areas with a thermocline and halocline (Fig. 3). The low concentration of SW9 was also accompanied by thermocline and halocline (Fig. 3 and Fig. S6). It showed that stratification was one of the reasons hindering substance exchange and causing the low concentration of contaminants in surface water. Although the salinity variation was not obvious in $\mathrm{BB}$, the thermocline occurred with depth. The highest HFRs concentrations in BB indicated that the sewage emissions and water transportation from highly polluted waters 

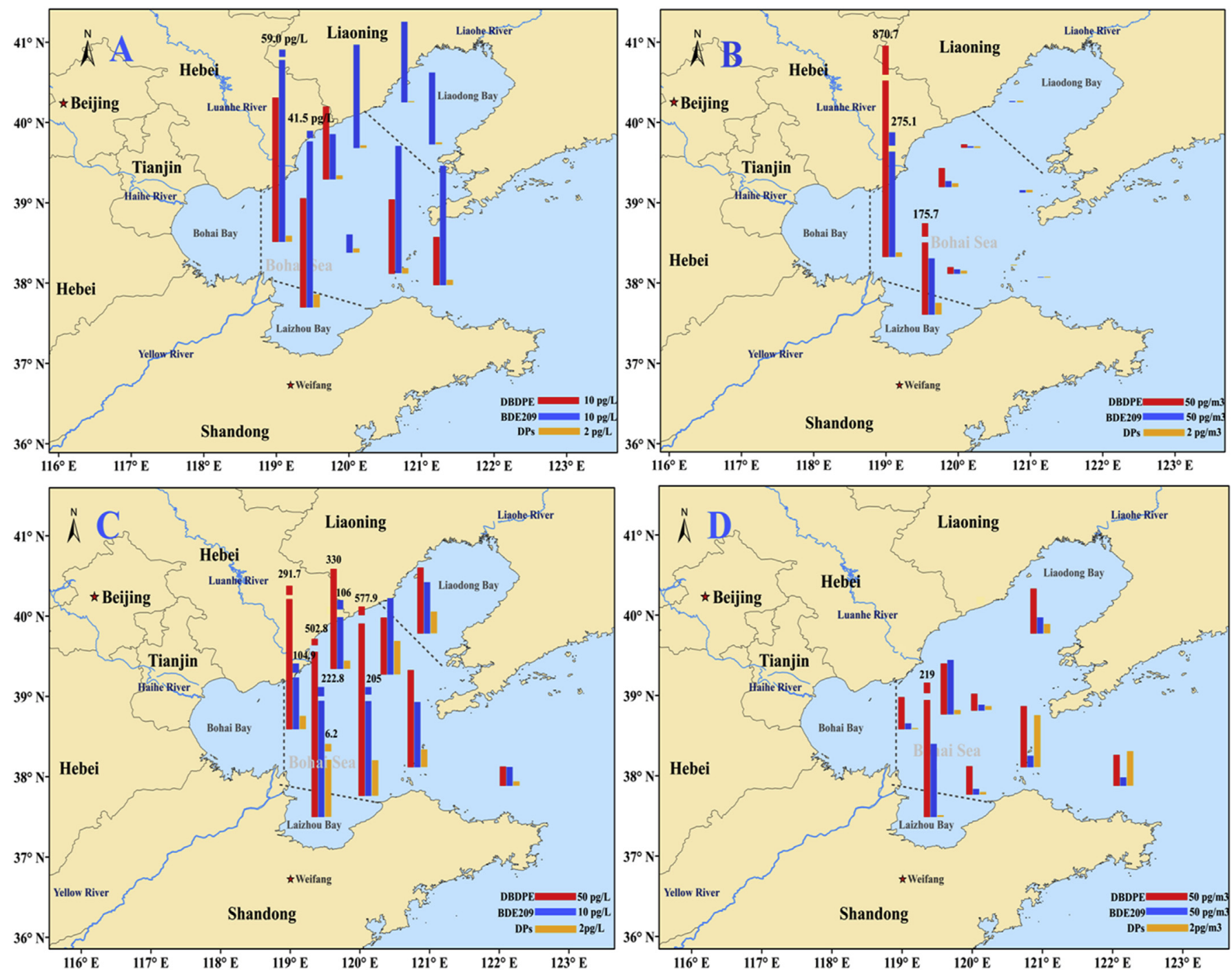

Fig. 1. Spatial distributions of the target compounds in the seawater (A/C) and atmosphere (B/D) samples in August (first row) and December (second row).
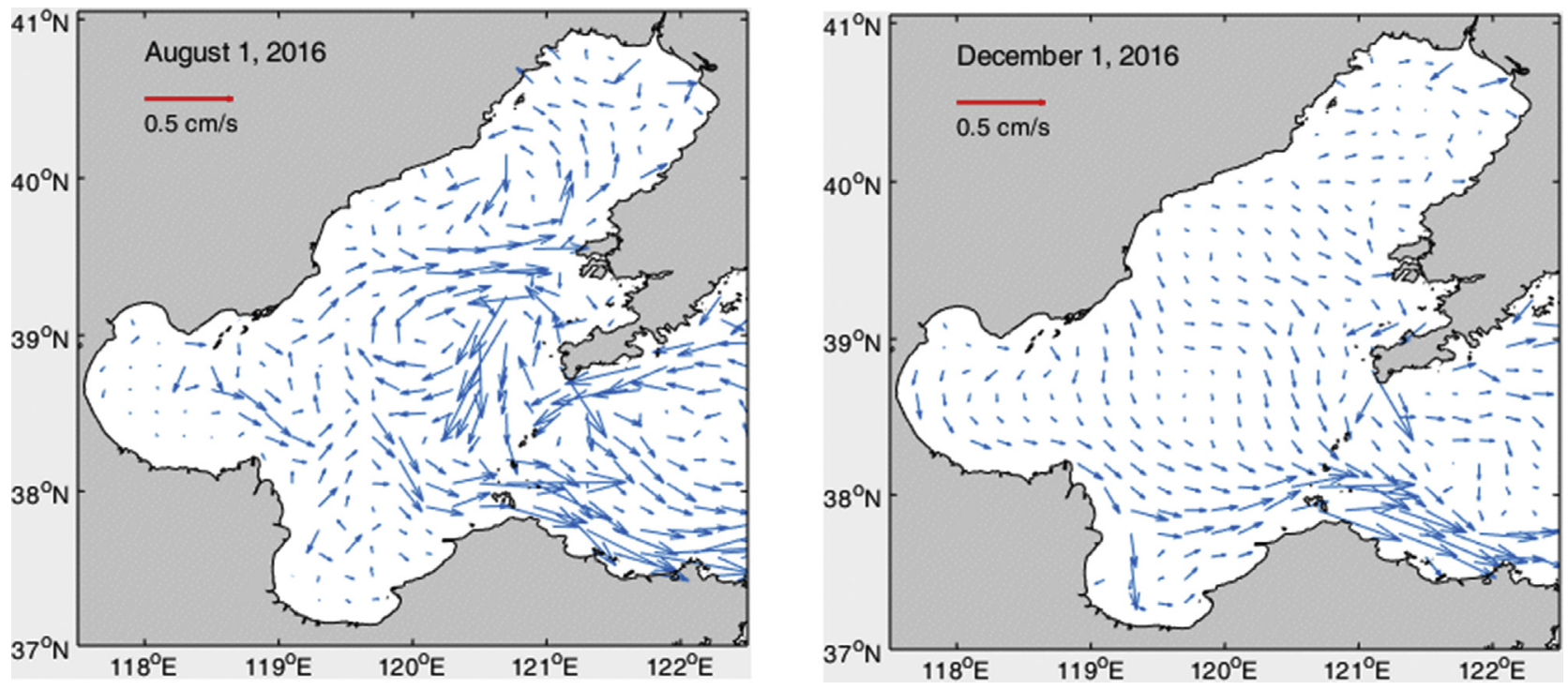

Fig. 2. Distribution of residual current in the surface layer in August and December 2016 (unit: $\mathrm{cm} \mathrm{s}^{-1}$ ). 

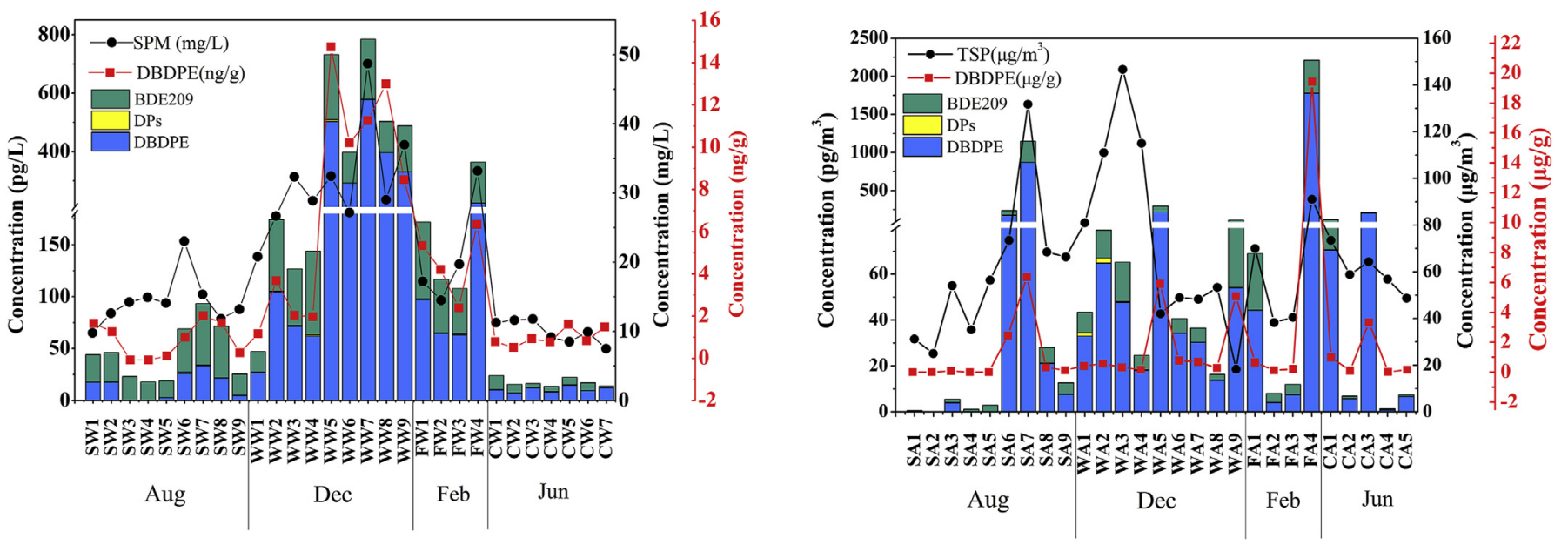

Fig. 3. Seasonal variations of HFR concentrations together with SPM in water (left) and TSP in air (right) samples in the Bohai Sea.

through coastal currents played a more important role in the contamination of HFRs in Bohai Sea (Fig. 3 and Fig. S6). In winter, there is no stratification of seawater due to the strong wind wave effect. The lowest concentration still appeared in the LDB and CBS, which would further explain the important impact of ocean current transport.

Although DBDPE shows higher mean levels than those of BDE209, there is an exception in August (Figs. S3 and S7). Results obtained by Fig. S7 indicate much higher concentrations of BDE209 than DBDPE in August in almost all sampling stations. The atmosphere and river are important vectors for POPs from terrestrial sources to the seawater (Zhao et al., 2020; Mulder et al., 2015). According to the samples collected from 31 rivers around the Bohai Sea in summer 2013, the total riverine input of BDE209 and DBDPE were estimated to be 140 and $19 \mathrm{~kg}$ season $^{-1}$ (unpublished data from our group), and the atmospheric deposition fluxes of them were 21 and $29 \mathrm{~kg}$ season $^{-1}$, respectively (details were shown in section 3.3 and Table S16). It has been verified that the runoff of rivers around Bohai Sea in summer accounts for $70 \%$ of the annual runoff (Wang et al., 2015). Thus, riverine inputs play a main role as BDE209 is transferred into the Bohai Sea, and this has contributed to the higher BDE209 levels in summer. For DBDPE, the absolutely high concentrations can be attributed to atmospheric deposition in other seasons.

\subsubsection{Seasonal patterns of HFRs in atmosphere}

Seasonal patterns of typical HFRs in the boundary layer of the Bohai Sea are shown in Fig. 3. No notable seasonality was found for HFRs in the atmosphere, but higher concentrations were observed in the particulate phase in December and February than those in August. A similar trend was observed in the atmosphere over the Yangtze River Delta and East China Sea (Li et al., 2015; Zhang et al., 2016), where the levels of PBDEs were both higher in winter. A possible reason for this is that the continental outflow from the land west and north of the Bohai Sea carried high levels of HFRs to the atmosphere. To further establish the relationship between the HFR concentrations and air masses, BTs of air masses were calculated to trace the most likely source paths of the air parcels. In December, February, and June, the air masses over the Bohai Sea were influenced by northerly and north-westerly winds that primarily originated from land, while in August, they were mainly influenced by southerly, south-westerly, and south-easterly winds that passed through Eastern China (Fig. 4 and Fig. S2). Most samples with elevated concentrations were associated with air masses passing over the North China, Mongolia, or Russia (Fig. 4 WA2, FA4), where the discharge of HFRs to the environment is higher due to the high level of production and/or usage. In summer, when southeasterly winds prevail, the atmospheric HFR concentrations were much lower in air masses from the open sea than in those from land (Fig. 4 SA4). When several air masses passed over the Bohai Rim in summer, the concentration of HFRs was higher and indicated that continental source pollution is an influencing factor (Fig. 4 SA6). During the sampling period, the high levels of HFRs were expected to be associated with the TSPs after their release to the air. Wang et al. (2014a,b) suggested that the high level of polycyclic aromatic hydrocarbons (PAHs) was influenced by increased TSP concentrations carried by the long-range transport of dust mixed with anthropogenic pollutants (Wang et al., 2014b). We calculated the TSP and DBDPE concentrations in particulate matter expressed in weight $\left(\mathrm{ng} \mathrm{g}^{-1}\right.$ ) (Table S11, Fig. 3). Although the correlations of these two targets were poor, nearly all sample cruises with higher abundances corresponded with notably increased TSP concentrations (Fig. 3 SA7, WA2, FA4, and CA3). This suggested that the TSP could cause variations in the concentrations of HFRs. Particulate air pollution measured reached levels considered hazardous to public health when elevated dose of PM (PM; 1.0, 2.5, 10 and TSP) during annual haze events (Adeniran et al., 2017). PBDEs concentration linearly increased with PM2.5 levels and decreased as a power function of the atmospheric boundary layer height (Cao et al., 2018). Therefore, hydrophobic organic pollutants, such as HFRs, could be carried by the large amount of particulate matter in haze during winter, which would aggravate air pollution, and special attention should be paid to the increased risk induced by elevated inhalation intake of HFRs during haze episodes.

\subsection{Atmospheric deposition fluxes}

Fig. S8 presents HFRs dry deposition fluxes $\left(\mathrm{ng} \mathrm{m}^{-2} \mathrm{~d}^{-1}\right)$ for each study region as estimated using equations (SI: $1-2$ ) and the details were shown in Table S14. The quarterly particle deposition fluxes in the entire Bohai Sea were estimated in $\mathrm{kg}_{\text {season }}{ }^{-1}$ and are shown in Table S16 (specific calculation processes in SI: statistic analysis). A degree of uncertainty is associated with this calculation due to the lack of field measurements of the deposition velocity and precipitation rate for the Bohai Sea. The overall dry flux was dominated

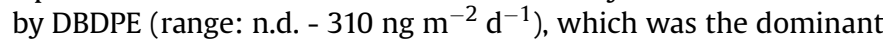
compound of the HFRs. The highest dry flux during all cruises (Fig. S8 F4: $380 \mathrm{ng} \mathrm{m}^{-2} \mathrm{~d}^{-1}$ ) was accompanied by the maximum 

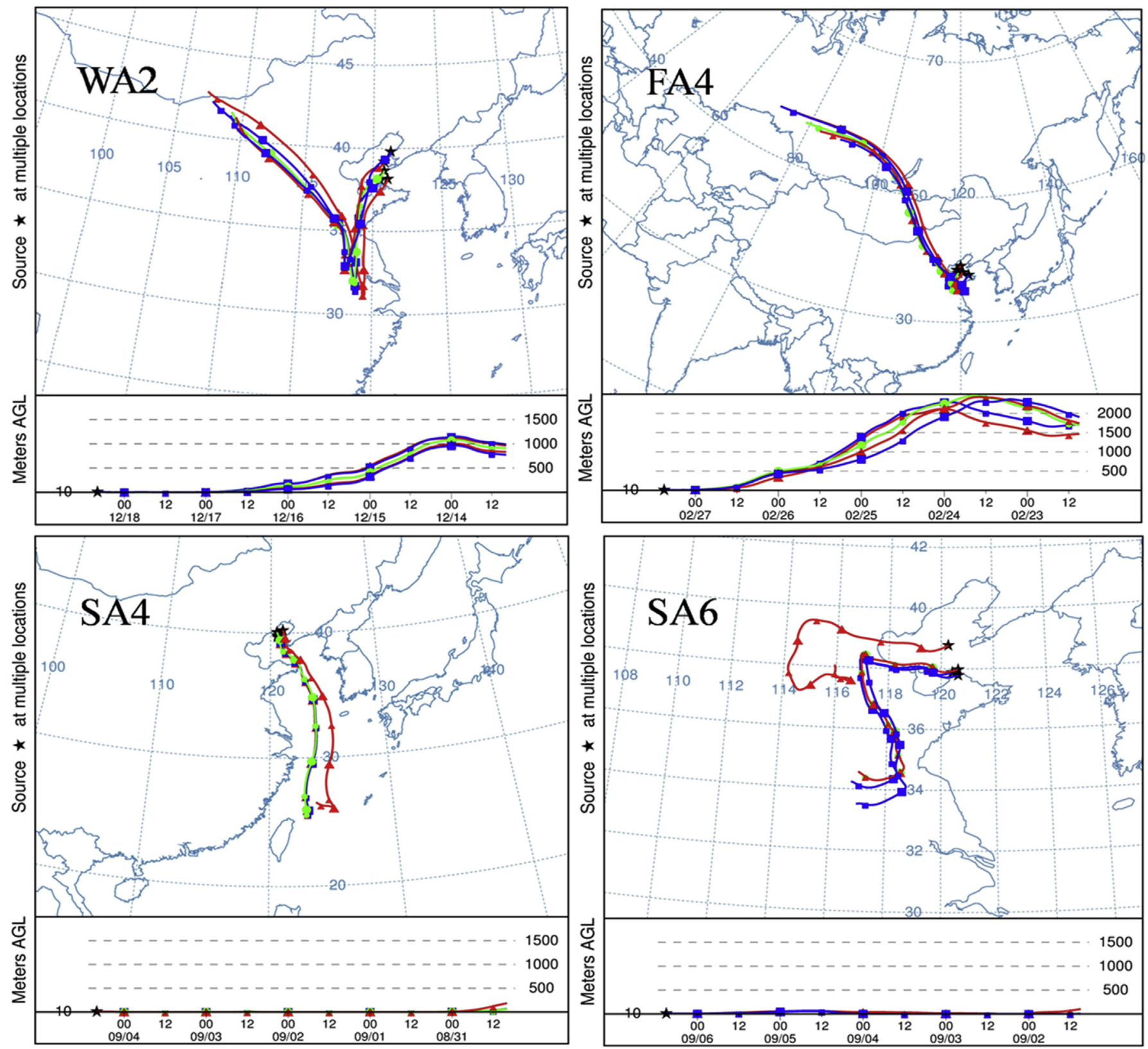

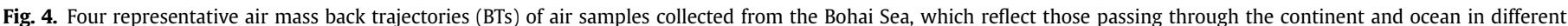
seasons. WA, FA, and SA represent the air masses in December (winter), February (winter), and August (summer).

wind speed (approximately $8.8 \mathrm{~m} \mathrm{~s}^{-1}$ ) measured onboard. This is consistent with the reports that increased wind speed accelerates the deposition of aerosol (Vento and Dachs, 2007). The high wet deposition fluxes for BDE209, DBDPE, and DPs in summer can be attributed to the washout behavior of rainfall, while the increasing levels of dry deposition in winter can be largely attributed to the significant influence of the increased TSP concentrations with relatively strong northerly and north-westerly winds from the continent. The estimated particle deposition fluxes of HFRs to the Bohai Sea were 19,51 , and $80 \mathrm{~kg}$ season ${ }^{-1}$ in spring, summer, and winter, respectively. This is the first estimation of the atmospheric deposition fluxes of HFRs into the Bohai Sea, which is, to a certain degree, influenced by chemicals that have a strong affinity to particulates.

\section{Conclusions}

This study presents a comprehensive investigation on the occurrence and seasonal variation of HFRs in seawater and atmosphere in the whole Bohai Sea, China. HRFs were mainly presently in the particulate phase and DBDPE and BDE209 were the dominant compounds both in atmosphere and seawater. Higher HFRs concentrations were found in the Laizhou Bay (near manufacturing area) than those in the Bohai Bay (near urban agglomerations, i.e. application area). HFRs in seawater exhibited significantly higher concentrations in winter than those in summer, the algae bloom in spring, water stratification summer, and sediment resuspension in winter control the seasonal variation of hydrophobic contaminants in shallow coastal sea. The composition of BDE209 and DBDPE 
varied largely in four sampling months, due to the contribution extents of riverine inputs and atmospheric depositions. High levels of HFRs were expected to be associated with high TSPs. Hydrodynamic conditions were predicted using the ROMS, suggesting the direction of pollutants in coastal seas was in accordance with the direction of current, which has transported HFRs from pollution sources to the Yellow Sea. Therefore, in the study of offshore contaminations, hydrodynamic factors cannot be ignored, and the data collected over a short period are insufficient to allow for an accurate ecosystem risk assessment of pollutants.

\section{Declaration of competing interest}

The authors declare that they have no known competing financial interests or personal relationships that could have appeared to influence the work reported in this paper.

\section{Acknowledgments}

This study was supported by the National Natural Science Foundation of China (No. 41773138 and U1806207), the seed project of the Yantai Institute of Coastal Zone Research, Chinese Academy of Sciences (No. YIC Y855011024), the Chinese Academy of Sciences (XDA11020402) and the Key Deployment Project of Centre for Ocean Mega-Science, Chinese Academy of Sciences (COMS2019J08).

\section{Appendix A. Supplementary data}

Supplementary data to this article can be found online at https://doi.org/10.1016/j.watres.2020.116117.

\section{References}

Adeniran, J.A., Aremu, A.S., Saadu, Y.O., Yusuf, R.O., 2017. Particulate matter concentration levels during intense haze event in an urban environment. Environ. Monit. Assess. 190 (1), 41.

Aznar-Alemany, O., Yang, X., Alonso, M.B., Costa, E.S., Torres, J.P.M., Malm, O., Barcelo, D., Eljarrat, E., 2018. Preliminary study of long-range transport of halogenated flame retardants using Antarctic marine mammals. Sci. Total Environ. 650 (Pt 2), 1889-1897.

Berrojalbiz, N., Dachs, J., Del Vento, S., Ojeda, M.J., Valle, M.C., Castro-Jimenez, J., Mariani, G., Wollgast, J., Hanke, G., 2011. Persistent organic pollutants in Mediterranean seawater and processes affecting their accumulation in plankton. Environ. Sci. Technol. 45 (10), 4315-4322.

Cao, R., Zhang, H., Zhao, L., Zhang, Y., Geng, N., Teng, M., Zou, L., Gao, Y., Ni, Y., Fu, Q. Chen, J., 2018. Hazy weather-induced variation in environmental behavior of PCDD/Fs and PBDEs in winter atmosphere of a north China megacity. Environ. Sci. Technol. 52 (15), 8173-8182.

Carlsson, P., Vrana, B., Sobotka, J., Borga, K., Bohlin Nizzetto, P., Varpe, O., 2018. New brominated flame retardants and dechlorane plus in the Arctic: local sources and bioaccumulation potential in marine benthos. Chemosphere 211, 1193-1202.

Cetin, B., Odabasi, M., 2007. Air-water exchange and dry deposition of polybrominated diphenyl ethers at a coastal site in Izmir bay, Turkey. Environ. Sci. Technol. 41, 785-791.

Covaci, A., Harrad, S., Abdallah, M.A., Ali, N., Law, R.J., Herzke, D., de Wit, C.A., 2011. Novel brominated flame retardants: a review of their analysis, environmental fate and behaviour. Environ. Int. 37 (2), 532-556.

Daniel, R.O., Dale, H., Francois, R., David, C., Jose, S., 2005. Levels and distribution of polybrominated diphenyl ethers in water, surface sediments, and Bivalves from the san Francisco estuary. Environ. Sci. Technol. 39, 33-41.

de la Torre, A., Barbas, B., Sanz, P., Navarro, I., Artinano, B., Martinez, M.A., 2018. Traditional and novel halogenated flame retardants in urban ambient air: gasparticle partitioning, size distribution and health implications. Sci. Total Environ. 630, 154-163.

Dong, Y., Fu, S., Zhang, Y., Nie, H., Li, Z., 2015. Polybrominated diphenyl ethers in atmosphere from three different typical industrial areas in Beijing, China. Chemosphere 123, 33-42.

Draxler, R.R., Rolph, G.D., 2003. HYSPLIT (Hybrid Single Particle Lagrangian Integrated Trajectory) Model.

Ge, W., Mou, Y., Chai, C., Zhang, Y., Wang, J., Ju, T., Jiang, T., Xia, B., 2018. Polybrominated diphenyl ethers in the dissolved and suspended phases of seawater from Sanggou Bay, east China. Chemosphere 203, 253-262.
Gu, S.Y., Ekpeghere, K.I., Kim, H.Y., Lee, I.S., Kim, D.H., Choo, G., Oh, J.E., 2017. Brominated flame retardants in marine environment focused on aquaculture area: occurrence, source and bioaccumulation. Sci. Total Environ. 601-602, $1182-1191$.

Haidvogel, D.B., Arango, H.G., Hedstrom, K., Beckmann, A., Malanotte-Rizzoli, P., Shchepetkin, A.F., 2000. Model evaluation experiments in the North Atlantic Basin: simulations in nonlinear terrain-following coordinates. Dynam. Atmos. Oceans 32 (3-4), 239-281.

Hainbucher, D., Hao, W., Pohlmann, T., Sündermann, J., Feng, S., 2004. Variability of the Bohai Sea circulation based on model calculations. J. Mar. Syst. 44 (3-4), $153-174$.

Jiang, W., Pohlmann, T., Sündermann, J., Feng, S., 2000. A modelling study of SPM transport in the Bohai Sea. J. Mar. Syst. 24 (3), 175-200.

Jin, J., Liu, W., Wang, Y., Yan Tang, X., 2008. Levels and distribution of polybrominated diphenyl ethers in plant, shellfish and sediment samples from Laizhou Bay in China. Chemosphere 71 (6), 1043-1050.

Jin, J., Wang, Y., Yang, C., Hu, J., Liu, W., Cui, J., Tang, X., 2009. Polybrominated diphenyl ethers in the serum and breast milk of the resident population from production area, China. Environ. Int. 35 (7), 1048-1052.

Jin, X., Lee, S., Jeong, Y., Yu, J.P., Baek, W.K., Shin, K.H., Kannan, K., Moon, H.B., 2016 Species-specific accumulation of polybrominated diphenyl ethers (PBDEs) and other emerging flame retardants in several species of birds from Korea. Environ. Pollut. 219, 191-200.

Ju, T., Ge, W., Jiang, T., Chai, C., 2016. Polybrominated diphenyl ethers in dissolved and suspended phases of seawater and in surface sediment from Jiaozhou Bay, North China. Sci. Total Environ. 557-558, 571-578.

Kierkegaard, A., Sellstrom, U., McLachlan, M.S., 2009. Environmental analysis of higher brominated diphenyl ethers and decabromodiphenyl ethane. J. Chromatogr. A 1216 (3), 364-375.

Lee, S.C., Sverko, E., Harner, T., Pozo, K., Barresi, E., Schachtschneider, J., Zaruk, D. DeJong, M., Narayan, J., 2016. Retrospective analysis of "new" flame retardants in the global atmosphere under the GAPS Network. Environ. Pollut. 217, 62-69.

Li, Y., Lin, T., Wang, F., Ji, T., Guo, Z., 2015. Seasonal variation of polybrominated diphenyl ethers in PM2.5 aerosols over the East China Sea. Chemosphere 119, 675-681.

Li, W.L., Huo, C.Y., Liu, L.Y., Song, W.W., Zhang, Z.F., Ma, W.L., Qiao, L.N., Li, Y.F., 2016a. Multi-year air monitoring of legacy and current-use brominated flame retardants in an urban center in northeastern China. Sci. Total Environ. 571, 633-642.

Li, Y., Zhang, H., Tang, C., Zou, T., Jiang, D., 2016b. Influence of rising sea level on tidal dynamics in the Bohai Sea. J. Coast Res. 74, 22-31.

Li, Q., Yang, K., Li, K., Liu, X., Chen, D., Li, J., Zhang, G., 2017. New halogenated flame retardants in the atmosphere of nine urban areas in China: pollution characteristics, source analysis and variation trends. Environ. Pollut. 224, 679-688.

Li, Y., Zhen, X., Liu, L., Tian, C., Pan, X., Tang, J., 2019. Halogenated flame retardants in the sediments of the Chinese Yellow Sea and East China sea. Chemosphere 234, 365-372.

Lu, L., Jiang, T., Xu, Y., Zheng, Y., Chen, B., Cui, Z., Qu, K., 2018. Succession of phytoplankton functional groups from spring to early summer in the central Bohai Sea using HPLC-CHEMTAX approaches. J. Oceanogr. 74 (4), 381-392.

Ma, W.L., Li, W.L., Zhang, Z.F., Liu, L.Y., Song, W.W., Huo, C.Y., Yuan, Y.X., Li, Y.F., 2017 Occurrence and source apportionment of atmospheric halogenated flame retardants in Lhasa City in the Tibetan Plateau, China. Sci. Total Environ. 607-608, 1109-1116.

Möller, A., Xie, Z., Caba, A., Sturm, R., Ebinghaus, R., 2012. Occurrence and airseawater exchange of brominated flame retardants and Dechlorane Plus in the North Sea. Atmos. Environ. 46, 346-353.

Mulder, M.D., Heil, A., Kukučka, P., Kuta, J., Přibylová, P., Prokeš, R., Lammel, G., 2015 Long-range atmospheric transport of PAHs, PCBs and PBDEs to the central and eastern Mediterranean and changes of PCB and PBDE congener patterns in summer 2010. Atmos. Environ. 111, 51-59.

Pan, X., Tang, J., Li, J., Guo, Z., Zhang, G., 2010. Levels and distributions of PBDEs and PCBs in sediments of the Bohai Sea, north China. J. Environ. Monit. 12 (6), 1234-1241.

Pan, X., Tang, J., Li, J., Zhong, G., Chen, Y., Zhang, G., 2011. Polybrominated diphenyl ethers (PBDEs) in the riverine and marine sediments of the Laizhou Bay area, North China. J. Environ. Monit. 13 (4), 886-893.

Qi, H., Li, W.-L., Liu, L.-Y., Zhang, Z.-F., Zhu, N.-Z., Song, W.-W., Ma, W.-L., Li, Y.-F., 2014. Levels, distribution and human exposure of new non-BDE brominated flame retardants in the indoor dust of China. Environ. Pollut. 195, 1-8.

Qiao, L., Zhong, Y., Wang, N., Zhao, K., Huang, L., Wang, Z., 2016. Seasonal transportation and deposition of the suspended sediments in the Bohai Sea and Yellow Sea and the related mechanisms. Ocean Dynam. 66 (5), 751-766.

Qiao, L., Zheng, X.B., Yan, X., Wang, M.H., Zheng, J., Chen, S.J., Yang, Z.Y., Mai, B.X., 2017. Brominated flame retardant (BFRs) and Dechlorane Plus (DP) in paired human serum and segmented hair. Ecotoxicol. Environ. Saf. 147, 803-808.

Shao, M., Tao, P., Wang, M., Jia, H., Li, Y.F., 2016. Trophic magnification of polybrominated diphenyl ethers in the marine food web from coastal area of Bohai Bay, North China. Environ. Pollut. 213, 379-385.

Su, X., Li, Q., Feng, J., Guo, L., Sun, J., 2017. Legacy and emerging halogenated flame retardants in the middle and lower stream of the Yellow River. Sci. Total Environ. 601-602, 1619-1627.

Sun, J., Liu, D., Qian, S., 2001. Preliminary study on seasonal succession and development pathway of phytoplankton community in the Bohai Sea. Acta Oceanogogica Sinica 20 (2), 251-260. 
Tao, F., Abou-Elwafa Abdallah, M., Ashworth, D.C., Douglas, P., Toledano, M.B., Harrad, S., 2017. Emerging and legacy flame retardants in UK human milk and food suggest slow response to restrictions on use of PBDEs and HBCDD. Environ. Int. 105, 95-104.

Unep, 2018. The 16 New POPs under the Stockholm Convention.

Vento, S.D., Dachs, J., 2007. Atmospheric occurrence and deposition of polycyclic aromatic hydrocarbons in the northeast tropical and subtropical Atlantic ocean. Environ. Sci. Technol. 41, 5608-5613.

Wang, Q., Kelly, B.C., 2017. Occurrence and distribution of halogenated flame retardants in an urban watershed: comparison to polychlorinated biphenyls and organochlorine pesticides. Environ. Pollut. 231, 252-261.

Wang, X., Cui, Z., Guo, Q., Han, X., Wang, J., 2009. Distribution of nutrients and eutrophication assessment in the Bohai Sea of China. Chin. J. Oceanol. Limnol 27 (1), 177-183.

Wang, R., Tang, J., Xie, Z., Mi, W., Chen, Y., Wolschke, H., Tian, C., Pan, X., Luo, Y., Ebinghaus, R., 2015. Occurrence and spatial distribution of organophosphate ester flame retardants and plasticizers in 40 rivers draining into the Bohai Sea, north China. Environmental Pollution 198, 172-178.

Wang, H., Wang, A., Bi, N., Zeng, X., Xiao, H., 2014a. Seasonal distribution of suspended sediment in the Bohai Sea, China. Continent. Shelf Res. 90, 17-32.

Wang, F., Lin, T., Li, Y., Ji, T., Ma, C., Guo, Z., 2014b. Sources of polycyclic aromatic hydrocarbons in PM2.5 over the East China Sea, a downwind domain of East Asian continental outflow. Atmos. Environ. 92, 484-492.

Wang, Y., Wu, X., Zhao, H., Xie, Q., Hou, M., Zhang, Q., Du, J., Chen, J., 2017a. Characterization of PBDEs and novel brominated flame retardants in seawater near a coastal mariculture area of the Bohai Sea, China. Sci. Total Environ. 580, 1446-1452.

Wang, X., Jin, C., Wang, L., Zhang, C., 2018. Distribution characteristics and influencing factors of particulate organic carbon in the Yellow Sea and the Bohai Sea in summer of 2016. Hai Yang Xue Bao 40 (10), 200-208.

Warner, J.C., Sherwood, C.R., Signell, R.P., Harris, C.K., Arango, H.G., 2008. Development of a three-dimensional, regional, coupled wave, current, and sedimenttransport model. Comput. Geosci. 34 (10), 1284-1306.
Wei, H., Sun, J., Moll, A., Zhao, L., 2004. Phytoplankton dynamics in the Bohai Sea-observations and modelling. J. Mar. Syst. 44 (3-4), 233-251.

Yang, Z., Ji, Y., Bi, N., Lei, K., Wang, H., 2011. Sediment transport off the Huanghe (Yellow River) delta and in the adjacent Bohai Sea in winter and seasonal comparison. Estuar. Coast Shelf Sci. 93, 173-181.

Zhang, L., Dong, L., Huang, Y., Shi, S., Yang, W., Zhou, L., 2016. Seasonality in polybrominated diphenyl ether concentrations in the atmosphere of the Yangtze River Delta, China. Chemosphere 150, 438-444.

Zhao, Y., Ma, J., Oiu, X., Lin, Y. Yang, Q., Zhu, T., 2013. Gridded field observations of polybrominated diphenyl ethers and decabromodiphenyl ethane in the atmosphere of north China. Environ. Sci. Technol. 47 (15), 8123-8129.

Zhao, H.D., Kao, S.J., Zhai, W.D., Zang, K.P., Zheng, N., Xu, X.M., Huo, C., Wang, J.Y., 2017. Effects of stratification, organic matter remineralization and bathymetry on summertime oxygen distribution in the Bohai Sea, China. Continent. Shelf Res. 134, 15-25.

Zhao, Z., Cheng, X., Hua, X., Jiang, B., Tian, C., Tang, J., Li, O., Sun, H., Lin, T., Liao, Y., Zhang, G., 2020. Emerging and Legacy Per- and Polyfluoroalkyl Substances in Water, Sediment, and Air of the Bohai Sea and its Surrounding Rivers, vol. 263, p. 114391 (Pt A)

Zhen, X., Tang, J., Xie, Z., Wang, R., Huang, G., Zheng, O, Zhang, K., Sun, Y., Tian, C. Pan, X., Li, J., Zhang, G., 2016. Polybrominated diphenyl ethers (PBDEs) and alternative brominated flame retardants (aBFRs) in sediments from four bays of the Yellow Sea, North China. Environ. Pollut. 213, 386-394.

Zhen, X., Tang, J., Liu, L., Wang, X., Li, Y., Xie, Z., 2018. From headwaters to estuary: distribution and fate of halogenated flame retardants (HFRs) in a river basin near the largest HFR manufacturing base in China. Sci. Total Environ. 621, $1370-1377$.

Zheng, B., Zhao, X., Ni, X., Ben, Y., Guo, R., An, L., 2016. Bioaccumulation characteristics of polybrominated diphenyl ethers in the marine food web of Bohai Bay. Chemosphere 150, 424-430.

Zhong, M., Tang, J., Mi, L., Li, F., Wang, R., Huang, G., Wu, H., 2017. Occurrence and spatial distribution of organophosphorus flame retardants and plasticizers in the Bohai and Yellow Seas, China. Mar. Pollut. Bull. 121 (1-2), 331-338. 